\title{
GESTÃO DO CONHECIMENTO: UM ESTUDO EM FRANQUIAS DE ESCOLAS DE IDIOMAS
}

\section{KNOWLEDGE MANAGEMENT: A STUDY ON LANGUAGE SCHOOL FRANCHISES}

\author{
Rita de Cássia Leal Campos \\ Centro Federal de Educação Tecnológica de Minas Gerais - CEFET-MG \\ rita.campos.adm@gmail.com
}

Marcella Barbosa Miranda Teixeira

Centro Federal de Educação Tecnológica de Minas Gerais - CEFET-MG

marcellabmt@gmail.com

Luana Jéssica Oliveira Carmo

Centro Federal de Educação Tecnológica de Minas Gerais - CEFET-MG

luanajeoli@gmail.com

Lilian Bambirra de Assis

Centro Federal de Educação Tecnológica de Minas Gerais - CEFET-MG

$\underline{\text { lilian@ cefetmg.br }}$

Submissão: $12 / 08 / 2018$

Aprovação: 13/01/2019

\begin{abstract}
RESUMO
Este artigo trata do estudo do conhecimento como recurso estratégico no contexto de redes de franquias de escolas de idiomas. $\mathrm{O}$ objetivo foi analisar a percepção dos franqueados em relação ao processo de transferência do know-how no sistema de franquias. A base teórica do estudo foi construída a partir dos temas: gestão do conhecimento, sistema de franquias e transferência de conhecimento nas franquias. Trata-se de uma pesquisa qualitativa descritiva que utilizou como método de coleta de dados a entrevista semiestruturada. Os dados foram analisados por meio da análise de conteúdo, sendo os resultados divididos em categorias. Foram entrevistados três franqueados de três marcas de franquias distintas em diferentes regiões. Como resultados, percebeu-se que o conhecimento é transmitido a partir de estruturas formais e informais, sobre as quais a tecnologia exerce impacto significativo. Os principais fatores que dificultam a transferência são os altos custos de treinamentos, o cumprimento dos requisitos exigidos e a redução do contato com o franqueador ao longo do tempo. Verificou-se também a existência de rigidez quando se trata da inovação, já que a unidade deve se encaixar
\end{abstract}


nos padrões da franquia e o franqueado não tem liberdade para implantar medidas sem a autorização do franqueador, apesar de ter suas sugestões ouvidas.

Palavras-chave: Gestão do conhecimento. Franquias. Transferência de conhecimento.

\begin{abstract}
This article deals with the study of knowledge as a strategic resource in the context of franchise networks of language schools. The objective was to analyze the perception of franchisees in relation to the process of transfer of know-how in the franchise system. The theoretical basis of the study was based on the themes: knowledge management, franchising system and knowledge transfer in the franchises. This is a descriptive qualitative research that used as a method of data collection the semi-structured interview. The data were analyzed through content analysis, the results being divided into categories. Three franchisees from three different franchise brands were interviewed in different regions. As results, it has been realized that knowledge is transmitted from formal and informal structures, on which technology has a significant impact. The main factors that hamper the transfer are the high cost of training, the fulfillment of the required requirements and the reduction of the contact with the franchiser over time. There has also been rigidity when it comes to innovation, since the unit must fit the franchise standards and the franchisee is not free to implement measures without the authorization of the franchisor, despite having his suggestions heard.
\end{abstract}

Keywords: Knowledge management. Franchises. Transfer of knowledge. 


\section{INTRODUÇÃO}

Reconhecido como um dos principais bens intangíveis de uma empresa, o conhecimento vem sendo estudado em contextos organizacionais que fomentam a inovação e agregação de valor por meio da alavancagem do patrimônio intelectual. $\mathrm{O}$ foco em ativos tangíveis no período industrial deslocou-se para a gestão dos ativos intangíveis na Era da Informação, tornando o conhecimento um fator chave de competitividade nas organizações (STEFANO et al., 2014).

$\mathrm{Na}$ visão de Nonaka e Takeuchi (1997) conhecimento é um processo humano dinâmico em que se justifica a crença pessoal em relação à verdade. O conhecimento se desenvolve por meio da experiência absorvida ao longo do tempo e seus componentes básicos são: a experiência, a verdade, o discernimento e as normas práticas. O conhecimento pode ser classificado em tácito e explícito. O tácito é bastante pessoal, entendido como crenças pessoais, valores e experiências individuais, e dificilmente pode ser expresso por palavras; a sua transmissão é complexa, pois é fruto de uma longa convivência e exige muitas interações. O explícito, por sua vez, é mais fácil de ser codificado, ou seja, transformado em palavras ou números, podendo ser rapidamente transmitido formalmente e em grande escala, por meio de documentos, manuais, dentre outros (NONAKA; TAKEUCHI, 1997).

O conhecimento é um fator competitivo para a organização, pois a forma como se dá a sua criação e compartilhamento são determinantes para a valorização do capital intelectual. A Gestão do Conhecimento (GC), portanto, é o processo de criar e disseminar conhecimentos incorporando-os a novos produtos, serviços, tecnologias e sistemas (NONAKA; TAKEUCHI, 1997). Korowajczuk et al. (2000) afirmam que a Gestão do Conhecimento (GC) é um processo destinado a promover o desempenho global da organização com base no conhecimento. Para Santos et al. (2001), a GC surgiu dentro das organizações como conceito nos anos 1990, associada principalmente à estratégia organizacional, podendo ser definida como o processo sistemático de criar, renovar e aplicar conhecimentos estratégicos para a organização. Essa administração dos ativos de conhecimento permite às organizações agregar valor à informação e tomar decisões mais acertadas em relação às melhores estratégias.

Nas empresas brasileiras, a gestão do recurso "conhecimento" tem sido fundamental para seu desempenho e sobrevivência aos desafios impostos pela abertura econômica. Essa é uma abordagem que implica o gerenciamento sistêmico dos esforços individuais e organizacionais, envolvendo aspectos ligados à alta administração, cultura, estrutura organizacional, recursos humanos, sistemas de informação e mensuração de resultados (TERRA, 2000).

A gestão do conhecimento pode ser compreendida a partir de duas grandes dimensões: a da tecnologia da informação e a do conhecimento em uma perspectiva social. A tecnologia da informação é utilizada pelas organizações como ferramenta de gestão, voltada para a sistematização e o gerenciamento dos dados. É um importante instrumento de apoio à incorporação do conhecimento como principal agregador de valor aos produtos, processos e serviços. Por outro lado, o foco da gestão do conhecimento também pode residir na criação de um ambiente favorável à comunicação e às condições essenciais para a formação e transmissão de conhecimento (ROSSETTI; MORALES, 2007).

A integração entre essas suas vertentes é considerada complexa, já que envolve a gestão tanto de ativos intangíveis quanto de conhecimentos estruturais e sistemas de informação de base tecnológica (ROSSETTI; MORALES, 2007). A Gestão do Conhecimento é uma disciplina mutável, dessa forma, não existe uma receita única para a sua aplicação em 
organizações diferentes, já que cada contexto tem suas peculiaridades e, portanto, exige intervenção específica (SANTOS et al., 2001).

Em um estudo recente, Cherman e Rocha-Pinto (2016) analisaram a percepção de membros organizacionais sobre como o conhecimento é experimentado e incorporado nas rotinas. Os resultados apontaram que a cultura e os valores dominantes moldam o modo de pensar, ser e agir dentro das organizações. Segundo Lara (2004) a gestão do conhecimento no meio organizacional fornece às pessoas que participam da tomada de decisão diariamente a capacidade intelectual da empresa, o que de forma conjunta pode determinar o sucesso ou fracasso do negócio. A gestão do conhecimento contribui para o desenvolvimento de organizações voltadas para a inovação e para a geração, disseminação e absorção do conhecimento. Assim, pode favorecer modelos de negócio como as franquias, ao dinamizar seus fluxos de informação entre franqueador e franqueado.

As franquias representam um tipo de negócio que vem apresentando expansões no mercado brasileiro nos últimos anos. De acordo com o relatório da Associação Brasileira de Franchising - ABF (2017), esse setor apresentou um crescimento de $8 \%$ no faturamento de 2017, atingindo uma receita de 163,319 bilhões. O franchising teve início por volta de 1860 nos Estados Unidos, entretanto, só ganhou popularidade no Brasil a partir de 1985. Dentre as pioneiras estão principalmente escolas de idiomas e lojas de perfumaria e cosméticos. A partir de 1990, o setor cresceu significativamente e foi sancionada a Lei de Franquias em 1994 (PÉRSICO; PAULA, 2013).

A lei brasileira 8.955 de 1994, que dispõe sobre o contrato de franquias, define em seu artigo segundo que "franquia empresarial é o sistema pelo qual um franqueador cede ao franqueado o direito de uso de marca ou patente, associado ao direito de distribuição exclusiva ou semi-exclusiva de produtos ou serviços" (BRASIL, 1994).

Coughlan et al. (2012) afirmam que, com a compra da licença para uma franquia, adquire-se o nome da marca e uma explicação por parte do franqueador de todas as decisões de marketing do negócio. Além de treinamento e assistência para a implementação, esse pacote inclui pesquisa de mercado, design e layout da instalação, consultoria financeira, manuais operacionais, programas de treinamento de gestão e dos funcionários do franqueado. De acordo com a International Franchise Association - IFA (2018), a essência da franquia está relacionada ao valor da marca, da forma como o franqueador dá suporte a seus franqueados e como estes cumprem suas obrigações para entregar produtos ou serviços nos padrões da marca.

De um lado, tem-se o esforço dispendido pela franqueadora para a transmissão de normas e padrões de produtos e serviços a fim de agregar valor à sua marca. Do outro lado, existem os interesses dos franqueados, que utilizam o conhecimento absorvido para posicionar-se competitivamente no mercado e obter o retorno econômico esperado com o investimento. Portanto, o relacionamento entre a franqueadora e as franqueadas precisa ser administrado para gerar resultados satisfatórios para todos os integrantes da rede (FEITOSA, 2010).

O sucesso do franchising é resultado da socialização dos resultados da rede e da profissionalização do sistema de distribuição com a real cessão de know-how pelo franqueador. Essa integração tem o objetivo de maximizar os resultados globais do sistema em busca de maior competitividade para a rede e não uma disputa interna por bons resultados de um membro em detrimento de outro. Assim, o desafio de se manter no mercado depende do relacionamento entre as partes no processo de transferência de conhecimento, o qual deve estar fundamentado em um senso de solidariedade e busca por soluções ganha-ganha (MAURO, 2007). 
Para Feitosa (2010), as franquias se expandem com base no gerenciamento estratégico do conhecimento, já que esse é transmitido pela franqueadora às unidades. Tal transferência ocorre por diferentes métodos de modo a garantir que o modelo de negócio seja replicado com sucesso. Sendo assim, o relacionamento entre franqueador e franqueado deve se pautar no diálogo e na cooperação, buscando estabelecer um ambiente de troca harmônico dentro da rede e um alinhamento de interesses entre seus participantes.

Levando em consideração tais discussões sobre a gestão do conhecimento no contexto das franquias, levanta-se a seguinte questão como problema de pesquisa: Qual a percepção dos franqueados em relação ao processo de transferência do know-how da franqueadora para as unidades franqueadas?

O objetivo geral consiste em analisar a percepção dos franqueados em relação ao processo de transferência do know-how no sistema de franquias. Para isso, propôs-se identificar os mecanismos utilizados para o compartilhamento do conhecimento e, além disso, apontar fatores facilitadores e dificultadores dos processos de transferência e absorção do conhecimento, evidenciando os desafios do franqueado quando se trata de gerir o conhecimento.

\section{MATERIAIS E MÉTODOS}

Considerando a questão que norteia esta pesquisa: Qual a percepção dos franqueados em relação ao processo de transferência do know-how da franqueadora para as unidades franqueadas? É fundamental salientar aspectos relacionados a transferência do conhecimento nas organizações para embasar a análise dos dados.

Para Alavi e Leidner (2001) o processo de transferência de conhecimento ocorre em vários níveis: entre indivíduos, de indivíduos para fontes explícitas, de indivíduos para grupos e do grupo para a organização. Algumas questões a serem observadas nesse processo são: (1) de que forma o conhecimento pode ser efetivamente transferido entre as unidades organizacionais, (2) até que ponto a aplicação da tecnologia da informação auxilia a transferência de conhecimento entre indivíduos dentro de um grupo e entre grupos, (3) quais estratégias organizacionais e técnicas são eficazes para facilitar a transferência do conhecimento e (4) quais atributos sociais, culturais ou técnicos encorajam e equilibram a transferência entre o provedor e o receptor do conhecimento.

A capacidade de absorção do conhecimento fundamenta-se em quatro dimensões. A primeira é a aquisição, que envolve a obtenção do conhecimento externo, essencial para as operações da organização. A segunda, conhecida como assimilação, relaciona-se à capacidade de processar, interpretar e compreender o conhecimento adquirido. A terceira é a transformação e diz respeito à combinação do conhecimento já existente com o conhecimento externo assimilado. A última dimensão, a exploração, enfatiza a aplicação do conhecimento transformado nas operações da empresa (ZAHRA; GEORGE; 2002). O quadro 1 apresenta as dimensões: 
Quadro 1 - Dimensões da capacidade de absorção

\begin{tabular}{|c|c|c|c|}
\hline \multicolumn{5}{|c|}{ Dimensões } \\
\hline Aquisição & Assimilação & Transformação & Exploração \\
\hline É a capacidade de & É a capacidade da & É a capacidade de & É a capacidade de \\
avaliação do uso do & organização em & internalizar o & aplicar o \\
conhecimento e & compreender o & conhecimento, com a & conhecimento \\
também de transferir & conhecimento & combinação do seu & adquirido, \\
o conhecimento de & externo à empresa. & conhecimento & assimilado e \\
uma organização & & anterior com o novo & transformado em \\
para outra. & & adquirido. & $\begin{array}{c}\text { rinas e operações } \\
\text { para uso } \\
\end{array}$ \\
& & & organizacional. \\
\hline
\end{tabular}

Fonte: Adaptado de Jiménez-Barrionuevo, García-Morales e Molina (2011)

Nas franquias, um exemplo de conhecimento que é transferido em um primeiro momento refere-se à gestão da unidade, que compreende tarefas administrativas, operacionais e mercadológicas. Posteriormente, podem ocorrer outros tipos de transferência como o conjunto de informações desenvolvido pelo franqueado no seu mercado local e/ou experiências profissionais anteriores à compra da franquia (GIGLIOTTI, 2010).

A transferência de know-how, embora fundamental para o sucesso do sistema de franquias, representa um desafio, pois muitos são os fatores que podem prejudicar esse processo. Szulanski (1996) classifica algumas destas barreiras em quatro dimensões: (1) inerentes ao conteúdo do conhecimento, que se relacionam à não compreensão do cenário em que o conhecimento se aplica (2) inerentes ao contexto, ou seja, à dificuldade de relacionamento entre as fontes (3) inerentes à fonte emissora, que estão ligadas à falta de motivação e credibilidade atribuída a ela e (4) inerentes à fonte receptora, a qual pode ter dificuldade em absorver e reter o conhecimento.

Sobre tais barreiras que interferem na capacidade de absorção das empresas Kogut e Zander (1992) afirmam que, dependo do contexto em que se encontram, as organizações apresentam posições divergentes. No nível intraorganizacional criam-se meios para eliminar as barreiras para a disseminação do conhecimento de valor, das melhores práticas, competências e habilidades independentemente de serem retidos por indivíduos, grupos ou unidades organizacionais. Em contrapartida, no nível interorganizacional, as empresas criam meios para proteger da concorrência os seus produtos, serviços, patentes, tecnologias, processos e colaboradores.

Em um estudo sobre a intensidade das barreiras referentes à transferência de conhecimento entre franqueador e franqueado, Araújo e Popadiuk (2015) constataram que quanto menos frequente é o contato entre as duas partes para ajustes operacionais, compartilhamento de novas informações e reflexões para implementação de estratégias de gestão menor é a probabilidade de utilização adequada do padrão exigido pelo franqueador.

Nesse sentido, Abdala e Gonçalves (2014) atentam para uma nova visão em que ambas a franqueadora e a fraqueada são responsáveis pelo processo de transmissão de conhecimento. Essa perspectiva se baseia no argumento de que é possível que as franquias se mantenham flexíveis, inovadoras e competitivas por meio de um processo de aprendizagem contínua que engloba toda a rede. Assim, a transferência de conhecimento se dá um uma via de mão dupla, em que o franqueado não apenas absorve, mas também repassa conhecimento ao franqueador. 


\subsection{Procedimentos metodológicos}

A metodologia deste estudo envolve uma pesquisa do tipo descritiva, que segundo Vergara (2013) tem o objetivo de expor as características de uma dada população ou fenômeno. Quanto à natureza, trata-se de uma pesquisa qualitativa. Ao adotar a abordagem qualitativa, o pesquisador parte da premissa que o mundo deriva da compreensão que as pessoas constroem no contato com a realidade das diferentes interações humanas e sociais. As ciências que estudam os homens e mulheres em seu cotidiano social constituem-se em domínios específicos de conhecimento, com métodos mais direcionados a compreensão da vida social (CHIZZOTTI, 2006).

Em relação aos procedimentos técnicos, adotou-se o método de estudos de casos múltiplos. Para Yin (2001), essa estratégia metodológica aumenta a validade externa da pesquisa e produz resultados mais convincentes. Além disso, é adequado quando se deseja investigar determinado fenômeno em profundidade e há múltiplas fontes de evidências que podem contribuir para a coleta e análise dos dados e ainda auxiliar no confronto entre a teoria e a prática. Segundo o autor, o estudo de caso é:

\footnotetext{
uma investigação empírica que investiga um fenômeno contemporâneo dentro de seu contexto de vida real, especialmente quando os limites entre o fenômeno e o contexto não estão claramente definidos (YIN, 2001, p. 32).
}

A escolha de se realizar múltiplos estudos de casos se justifica pela replicação literal e teórica que se espera para este estudo, ou seja, que os casos apresentados neste artigo possam predizer resultados similares, de modo que sejam validados externamente além do universo considerado. A confiabilidade deste estudo está pautada na demonstração de que os procedimentos da coleta de dados, no caso desta pesquisa as entrevistas semiestruturadas, podem ser repetidos apresentando os mesmos resultados (YIN, 2001).

$\mathrm{O}$ grupo de referência selecionado para a pesquisa inclui três marcas associadas à $\mathrm{ABF}$ do segmento escola de idiomas. Esse segmento foi escolhido em razão de seu pioneirismo no sistema de franquias. As marcas serão aqui denominadas como A, B e C. Na tabela 1 são apresentadas informações fornecidas pela $\mathrm{ABF}$ sobre tais marcas:

Tabela 1 - Caracterização das franqueadoras

\begin{tabular}{cccc}
\multirow{2}{*}{ Marcas } & Tempo de mercado & \multicolumn{2}{c}{ Número de unidades } \\
\cline { 3 - 4 } & & Brasil & Exterior \\
\hline A & 57 anos & 723 & 12 \\
B & 30 anos & 1231 & 10 \\
C & 18 anos & 234 & 1 \\
\hline
\end{tabular}

Fonte: Elaborado pelas autoras com base nos dados da ABF (2018) 
Foram pesquisadas três franqueadas do segmento de escolas de idiomas, sendo uma de cada marca. As empresas selecionadas possuem portes e estágios de maturidade distintos e, além disso, localizam-se em diferentes cidades. Dessa maneira, foi possível fazer análises e comparações no que diz respeito à gestão do conhecimento em redes diversas de um mesmo segmento de franquias.

A coleta de dados ocorreu a partir da realização de entrevistas semiestruturadas com os proprietários ou coordenadores das três franqueadas. Para a análise dos dados foi utilizada a análise de conteúdo. Em síntese, Bardin (2002, p. 42) define a análise de conteúdo como o "conjunto de técnicas de análise das comunicações visando obter, por procedimentos sistemáticos e objetivos indicadores que permitam a inferência de conhecimentos relativos às mensagens".

Funciona como um leque de ferramentas, podendo ser uma via de análise dos significados ou dos significantes, e possui uma função heurística, enriquecendo assim a pesquisa exploratória, por meio da descoberta. A análise de conteúdo caminha entre dois polos - entre o rigor da objetividade e a fecundidade da subjetividade. $\mathrm{O}$ investigador se atrai pelo oculto, o latente, o não aparente, o potencial inédito (não dito) presente em qualquer mensagem (BARDIN, 2002).

Para facilitar o entendimento de como a pesquisa está estruturada, apresentam-se no Quadro 2 as informações que a caracterizam em termos metodológicos:

\section{Quadro 2 - Síntese da metodologia utilizada}

\begin{tabular}{|c|c|c|c|c|c|}
\hline $\begin{array}{c}\text { Natureza da } \\
\text { pesquisa }\end{array}$ & $\begin{array}{c}\text { Delineamento da } \\
\text { pesquisa }\end{array}$ & $\begin{array}{c}\text { Entidades } \\
\text { estudadas }\end{array}$ & Coleta de dados & $\begin{array}{c}\text { Análise dos } \\
\text { dados }\end{array}$ & $\begin{array}{c}\text { Grupo de } \\
\text { referência }\end{array}$ \\
\hline $\begin{array}{c}\text { Descritiva } \\
\text { qualitativa }\end{array}$ & $\begin{array}{c}\text { Estudos de casos } \\
\text { múltiplos }\end{array}$ & $\begin{array}{c}3 \text { franquias de } \\
\text { escolas de } \\
\text { idiomas }\end{array}$ & $\begin{array}{c}\text { Entrevistas } \\
\text { semiestruturadas }\end{array}$ & $\begin{array}{c}\text { Análise de } \\
\text { conteúdo }\end{array}$ & Franqueados \\
\hline
\end{tabular}

Fonte: Dados da pesquisa

\section{RESULTADOS E DISCUSSÃO}

O referencial teórico forneceu embasamento para a formação de categorias de análise para este estudo, agrupando elementos, ideias e expressões em torno de conceitos capazes de sintetizar os dados coletados dos estudos de caso selecionados, Para a apresentação dos resultados, os dados foram distribuídos e analisados a partir das seguintes categorias: escolha pela franquia; transferência e absorção de conhecimento; tecnologia na gestão do conhecimento das franquias; inovação no sistema de franquias; e padronização no processo de gestão do conhecimento. Os franqueados entrevistados identificam-se como F1, F2 e F3 e representam as marcas $\mathrm{A}, \mathrm{B}$ e $\mathrm{C}$, respectivamente.

Antes de apresentar a análise das categorias, expõe-se um histórico das franquias pesquisadas. A franquia da F1 tem 25 anos de história. Sua atual proprietária e entrevistada dessa pesquisa era aluna da escola de idiomas, tornou-se professora e depois comprou a escola juntamente com duas sócias que também foram alunas e professoras. Verifica-se que a F1 
passou por muitas transformações e dificuldades. Quando a entrevistada assumiu a direção, a escola estava à beira da falência, então foi feito todo um trabalho de recuperação financeira, de credibilidade, bem como a mudança do espaço físico da escola para um local mais apropriado.

A franquia do F2 está no mercado desde 2009 e seu proprietário é um engenheiro, exfuncionário público, que estudou as franquias até optar pelo segmento de idiomas, que era um dos segmentos mais promissores na época. De acordo com o entrevistado, a franquia passou por muitas transformações devido à venda da marca para outra empresa, o que acarretou mudanças como maior abertura e contato mais frequente em relação aos franqueados.

Já a franquia da F3 está no mercado desde 2007. Seu diretor é também proprietário de outras unidades em diversas cidades e não fica na cidade em que a F3 está localizada. Por esse motivo, foi entrevistada a coordenadora e responsável por essa unidade. A grande dificuldade encarada pela F3 foi o fato de ser uma franquia nova entrando no mercado, dessa forma as pessoas não tinham muito conhecimento sobre a proposta. Além disso, a metodologia adotada por essa franquia era muito diferente daquelas utilizadas pelas escolas tradicionais.

\subsection{A escolha pela franquia}

Como destaca a IFA (2018), o sucesso da franquia está ligado ao valor da marca em questão e à maneira como o franqueador e o franqueado empregam seus esforços para entregar os produtos ou serviços dentro dos padrões. Para F1, o poder da franquia reside no reconhecimento da marca, onde quer que ela esteja presente e na qualidade do serviço entregue. A decisão da entrevistada de comprar a franquia se deu com base no conhecimento e confiança adquiridos durante os anos em que foi aluna e professora. A entrevistada ressalta que a marca está no mercado há 57 anos, e a franqueada, há mais de 20, o que representa um indicativo de sucesso.

Já o F2 escolheu uma franquia de idiomas por acreditar que é um mercado em crescimento e que seria perene:

Dentro da área de educação os idiomas era uma coisa que o país precisava e tinha uma demanda muito grande. O único gap, a dificuldade do idioma é a falta de relevância que as pessoas dão a ele, por exemplo, o idioma é só um cursinho na cabeça das pessoas, é como uma academia, se não for não tem problema. $\mathrm{Na}$ verdade, ele não é exatamente assim né. Hoje ele traz mais resultados do que uma graduação. Ele tem trazido né, eu não acho, eu tenho certeza. Hoje as propostas de trabalho ou até de remuneração são melhores para quem tem o idioma [...] (F2).

Mas, antes de decidir sobre qual marca ele se tornaria franqueado, optou por fazer um teste como aluno em algumas escolas de idiomas (franquias) para verificar como era a experiência dele com o produto, o que mais chamou a sua atenção e o levou a decidir pela marca foi o método:

E eu fiz um negócio interessante, eu me matriculei em outras marcas e nessa. Fiz um experimento de alguns poucos meses, paguei, para experimentar o produto porque se eu não acredito no produto eu não vendo, ele não tem, e não que os outros sejam ruins, é que essa para mim foi a melhor, ela funcionou melhor, dentro de sala de aula eu me senti melhor, não foi um bom professor, foi um bom método (F2).

Essa escolha por um método diferenciado não só chamou a atenção da $F 3$, como também foi o responsável por atrair clientes desde o início do funcionamento das atividades da empresa, segundo a entrevistada. 
E nossa metodologia também é diferente das escolas tradicionais, então acho que isso acabou chamando um pouco de atenção das pessoas que ainda não conheciam (F3).

\subsection{Transferência e absorção de conhecimento}

Os entrevistados foram perguntados sobre os métodos utilizados pela franqueadora para a transferência de conhecimento. Dessa forma, foi citado que as franqueadoras usam de treinamentos para repassar as mudanças e procedimentos, de encontros nacionais e regionais, além da tecnologia, com o contato por meio de intranet, e-mail, telefone, de rede social de troca de mensagens, plataformas e informativos.

Trata-se aqui do conhecimento explícito, que segundo Nonaka e Takeuchi (1997), pode ser transmitido em grande escala por meio de documentos e manuais. Já o conhecimento tácito, no caso das franquias, estaria mais relacionado à experiência pessoal de cada franqueado, adquirida ao longo do tempo com a gerência da franquia, compreendendo, por exemplo, as decisões rotineiras e a escolha das melhores estratégias para o negócio.

A gente tem uma intranet, em que todas as informações são passadas por lá. Há também encontros regionais, não são tão frequentes assim, mas acontecem a cada 2 anos mais ou menos, em que são passadas as novas diretrizes da empresa, são anunciadas novidades, essas coisas. E também a comunicação diária né, por e-mail, telefone, whatsapp (F1).

Eles fazem os congressos de franqueados para passar todas as informações e novidades. É anual. E outras formas é através de treinamentos, né, a gente uma competição interna que a gente faz entre as áreas, então tem encontros trimestrais, ne, de três em três meses a gente tem encontro que fala da competição interna, mas também abre espaço para treinamentos para que passe as informações para alinhamento (F3).

Ademais, na F3 verifica-se que o conhecimento é passado para o diretor, que repassa aos coordenadores das unidades das franquias e que repassam aos funcionários:

Normalmente, é passado para o diretor franqueado, o diretor franqueado passa para os coordenadores, porque a gente é um conjunto, mas acaba sendo dividido por áreas, né. E repassa para os coordenadores para aí sim passar para o restante dos funcionários $(\mathrm{F} 3)$.

De acordo com o F2, dentre as formas de transmissão de conhecimento existem também caravanas:

Falei para você da caravana, elas entraram há uma semana e por acaso a caravana foi há uns três, quatro dias atrás, com o pessoal da franquia, então teve um treinamento de um pessoal não é um cara qualquer, ele é bom, ele é muito bom, ele vem e passa dois dias com esse pessoal (F2).

Em seguida, perguntou-se se houve alguma mudança do contato com a franqueadora do início até agora. Verificou-se que:

$\mathrm{Na}$ verdade, ele é sempre mais frequente, né, com o conhecimento que a gente vai tendo, com as novidades, vai surgindo dúvidas. Então a gente tem o contato direto com a franquia $(\mathrm{F} 3)$.

$\mathrm{Na}$ franquia B, com a troca no grupo administrador mundial, houve uma melhoria no sentido de transmitir o conhecimento, já que segundo o entrevistado: 
[...] passou a ter um processo de profissionalização nesse sentido, antes era o método, literalmente o método, ninguém vinha te visitar. [...] E a gente era muito carente antes, entende? Todos têm muita carência de uma luz de "como eu faço", agora está melhor (F2).

O F2 deixa bem explícito essa necessidade do franqueado em receber o know how da empresa franqueadora e pelo depoimento dele, isso não é muito frequente:

É a reclamação de todo franqueado. Pessoa te ensina, te larga na mão com o produto te dá uma aula de duas semanas e "se vire nos 30". É a reclamação de todo franqueado de qualquer marca. Raras são as exceções (F2).

De acordo com a fala acima do F2, percebe-se que a capacidade de absorção de conhecimento da franquia em sua segunda, terceira e quarta dimensão, a assimilação que está relacionada à capacidade da empresa de processar, interpretar e compreender o conhecimento adquirido, a transformação que diz respeito à combinação do conhecimento já existente com o conhecimento externo assimilado e a exploração que enfatiza a aplicação do conhecimento transformado nas operações da empresa, conforme citado por Zahra e George (2002), está sendo prejudicada, pela falta de suporte após a aquisição do conhecimento da franqueada.

A F1 concorda que o contato se tornou menos frequente com o passar dos anos e ainda faz uma observação em relação aos manuais do franqueado. Esse material, que antes era enviado impresso pelo franqueador, hoje é disponibilizado apenas via intranet. Assim, a proprietária imprime aqueles mais importantes para facilitar o treinamento dos funcionários.

Já o contato entre o franqueador e o franqueado parece ser frequente de acordo com a fala da F3. Entretanto, pelo depoimento, tem-se a impressão de que parte mais da iniciativa do franqueado buscar o apoio da franqueadora.

Então a gente tem o contato direto com a franquia, por telefone, por e-mail, sempre que a gente tem algum problema eles dão todo suporte prontamente (F3).

Percebe-se pelas respostas dadas pelos entrevistados que há alguns desafios a serem enfrentados no processo de transferência de conhecimento, conforme cita Szulanski (1996). Dentre as barreiras citadas pelo autor, observa-se a dimensão relacionada à fonte emissora, já que para F2 há uma falta de acompanhamento do franqueador após os treinamentos, e à fonte receptora, uma vez que que as franqueadas podem ter dificuldades em absorver e aplicar o conhecimento adquirido nas franquias. Apesar disso F1 e F3 esclarecem que sempre que isso ocorre pode ser realizado o contato com o franqueador para suporte.

\subsection{A tecnologia na gestão do conhecimento das franquias}

De acordo com o F2, a tecnologia tem papel primordial, principalmente quando se trata da integração de novos funcionários:

[...] tem alguns treinamentos de plataforma EAD, são muito bons e a pessoa vai conhecendo cada dia um pouquinho mais. Tem um conteúdo bem direcionado, o que que são técnicas de ligação, o que é a marca, o que é a nossa política, o que essa campanha, como funciona aula, para que ela consiga absorver o máximo de conteúdo e consiga passar com credibilidade ao cliente (F2). 
A importância da tecnologia na transmissão do conhecimento ocorre em diversos vetores dentro da franquia, não só na direção franqueador - franqueado, como também franqueador - cliente, conforme afirmam F2 e F3:

É um sistema inteligente, não é tipo uma plataforma de internet com aqueles pontinhos ou não, se eu tiver acima de sete eu passo, se não, não. Ela te dá então por exemplo, se você estudou ali e tirou $70 \%$ em sala de aula da parte de fala, ou de leitura, tanto faz, ele vai criar um exercício para complementar os $30 \%$ que você deixou de cumprir. É um complemento para que você absorva 100\% do exercício (F2).

Nosso sistema foi criado também, um sistema próprio. O nosso material a gente acaba utilizando a internet para melhorar o aprendizado dos alunos. Então, acho que a tecnologia tem tudo a ver. E agora a gente começou a trabalhar com a realidade virtual aumentada também. Então, acho que a tecnologia também é o cargo chefe aí para a gente, nesse caso (F3).

Alavi e Leidner (2001) fazem um questionamento sobre até que ponto a tecnologia da informação auxilia a transferência de conhecimento. Na fala de F1 é possível perceber as "duas faces da mesma moeda". A entrevistada reconhece que a tecnologia tornou as informações mais acessíveis, destacando que consegue esclarecer qualquer dúvida com a franqueadora de maneira muito rápida. Contudo, afirma também que com a facilidade trazida pela tecnologia, as visitas de supervisão e os encontros regionais tornaram-se menos frequentes, reduzindo assim o contato pessoal:

Com as mudanças através do tempo, tanto as visitas quanto os encontros se tornaram desnecessários. Com relação à propaganda, a gente decide tudo por e-mail, por uma pesquisa do tipo survey, ali já resolve tudo e não tem necessidade de ter o encontro. Ali eles já verificam com a rede toda, discute, tem os resultados e passam para gente. Eu particularmente acho importante manter esse contato pessoal, sempre fizemos o possível para poder ir e participar porque a gente sabe da importância. Então a diferença de quando começou para hoje em dia é que antes a gente tinha esse contato pessoal muito maior. Esses encontros eram uma oportunidade para os franqueados, para trocar ideia, ver o que um está fazendo e está funcionando e adaptar e buscar. Por mais que eram encontros do franqueador a gente não deixava de trocar experiência com os franqueados, então tinha esse aspecto positivo (F1).

\subsection{Inovação no sistema de franquias}

Tendo em vista a relação entre inovação e gestão do conhecimento, foi perguntado aos entrevistados se há espaço para inovação no sistema de franquias. Para a F3 a inovação está sempre presente nos processos da franquia, entretanto é um processo de responsabilidade dos franqueadores.

Para a F1, existe espaço para a inovação, porém:

[...] as mudanças não acontecem "a toque de caixa" é uma questão de responsabilidade do franqueador com a marca. As coisas acontecem no tempo que eles entendam que deve ser, não atropelar, porque a gente tem um nome a zelar, a gente tem uma qualidade que é reconhecida pelo mercado então não há razão para gente fazer as coisas de qualquer jeito. Espaço para inovação sempre tem.

O F2 afirma que existe sim inovação por parte da franqueadora e que as franquias de escolas de idiomas precisam inovar para continuarem no mercado: 
Acho que existe e acho que as coisas têm que evoluir sim. Todas as marcas que chegaram num ponto de arrogância de achar que ninguém poderia tirar eles de lá foram ultrapassadas. [...] Mesma coisa acontece com as franquias, é um exemplo de mercado, se não se adequa às necessidades de um novo público, morre, como aconteceu com muitos outros.

Foi questionado se as franqueadoras estão abertas a sugestões de seus franqueados. Percebe-se diferentes visões nessa questão:

Como é uma franquia e é uma franquia grande é difícil mesmo, todo mundo dá palpite, são muitos lugares, a franquia está no Brasil inteiro, cada realidade é diferente. O que vem de sugestões nossas, de funcionários e alunos a gente normalmente repassa, mas já sabendo que não é uma coisa que vai ser acatada e mudar amanhã. Até porque, por ser uma empresa muito grande ela tem que seguir suas próprias diretrizes, seus valores, é isso que norteia as ações da empresa. Não quer dizer que eles não nos ouçam, mas que alguma sugestão seja implementada ela passa por uma série considerável de estudos e avaliações primeiro (F1).

Agora sim, por isso que eu estou dizendo que teve muita mudança, os CEOs novos que entraram deram uma cara muito melhor. Antigamente era extremamente imperativo, não, de maneira nenhuma, ainda mais se eu confrontasse ele, ele dava um jeito de se livrar desse cara da marca. Essas histórias que eu escuto (F2).

Sim, eles, o que a gente tem, de alunos também, a gente repassa e eles analisam. [...] Então, na verdade sempre é com eles, essa questão de inovação é com eles. Então, eles repassam para gente (F3).

A partir dessas respostas foi possível inferir que, no sistema de franquias, as inovações partem do franqueador. Quando indagado se ele tem liberdade para inovar, a resposta do F2 foi que tudo o que vem do franqueado deve ser enviado para a análise do franqueador:

Já aconteceu de passarem por cima disso, não foi bom, não deu certo não foi aprovado e nunca mais aconteceu. A gente aprende com os erros né (F2).

\subsection{Padronização nos processos de gestão do conhecimento}

Para F3, os cursos e treinamentos estão relacionados à padronização de processos:

Nós temos cursos, né, a franqueadora nos tem dado muito suporte com treinamentos, a gente pode pedir para uma pessoa da franquia vir até a unidade para nos dar informações. Aí a gente também tem treinamento sempre que tem novidades, ne, fazer um mapeamento, então periodicamente a gente tem treinamentos para regularizar, na verdade para padronizar $(\mathrm{F} 3)$.

Para a entrevistada, há uma padronização e um processo de alinhamento feito pela franqueadora para que os procedimentos sejam feitos da mesma maneira em todas as unidades:

Eu acredito que todos são muito bem orientados e com esse alinhamento que eles fazem para que todas as unidades trabalhem da mesma forma, eu não vejo dificuldade. Eu acho que quando é tudo alinhadinho não tem muito erro. Quando sai do alinhamento é que acaba tendo um problema ou outro, mas trabalhar da forma que é proposto eu acho que não tem problema nenhum (F3). 

feito:

Foi questionado à F3 se acontece de algum processo sair da padronização e o que é

Às vezes acontece, ne? Às vezes a gente precisa contratar um funcionário novo que às vezes não se adequa à metodologia, ou à forma de trabalho, então pode acontecer por um período e a gente está observando para corrigir essas questões também.

Em relação à rigidez na padronização nas franquias, F1 se posiciona favoravelmente quanto a essa característica comum do processo. Para a entrevistada, isso é algo bom para a rede e para o cliente. Exemplificando esse aspecto, ela afirma que:

É rígido assim, no caso, a gente tem um padrão de cor de parede, tem o código da tinta, do azulejo que eu tenho que usar no meu manual de identidade visual. Qualquer alteração a ser feita tem que ser submetida e aprovada. Então nesse aspecto é rígido, mas tem que ser senão não é padrão.

\subsection{Dificultadores do processo de gestão do conhecimento na franquia}

De acordo com Santos et al. (2001), o principal desafio relacionado à gestão do conhecimento nas organizações é influenciar o comportamento das pessoas. Além disso, existem outras dificuldades ligadas aos seguintes aspectos: fazer com que as lideranças cumpram a ideia; classificar o conhecimento; e a tendência das pessoas de reter seus conhecimentos. Sobre fazer com que as lideranças cumprem a ideia, o F2 afirmou que é preciso um acompanhamento de perto:

Eu aprendi a conhecer cada detalhe, porque aquele negócio de ah, é só contratar quem sabe. Como você sabe se o serviço está indo bem feito, pelo resultado assim, está, arrisca, manda fazer para você ver se faz bem feito e ele não faz bem feito, de que bolso sai? [...] Então você tem que pelo menos saber o processo, você tem que saber, pra você saber se o seu líder está fazendo, está fazendo com que a equipe faça e opa, tá indo no caminho certo.

Além disso, para o F2, o grande dificultador da disseminação do conhecimento no sistema de franquias está relacionado aos altos custos para se fazer os cursos:

Esse é um dos dificultadores, tudo é muito caro. [...] O dificultador é que tudo gera um custo muito grande, muito exagerado (F2).

Esse MBA custa para você pagar o curso se não me engano 11 mil reais de uma vez. Sem contar que você faz 4 visitas em SP, aí você paga viagem 4 vezes de avião, então não sai menos de 14 mil reais para fazer esse curso, são 4 visitas de 1 dia e meio cada uma, então esse é um dificultador, porque eu quero ter um conhecimento a um bom nível [...] Foi bom, foi bom! Vai trazer um retorno? Vai, mas isso inibe, eu estou numa grande capital com uma escola de 500 alunos, mas se você pega um que está começando, eu conheço alguns que está pagando aluguel, que está sofrendo ainda... Ele está esperando o dinheiro dele voltar, está apertado aí eles falam assim para você ser um cara com bastante conhecimento e dar esse up, investe 15 mil agora, e não tem, e essa é a grande dificuldade de ficar ali raspando o chão até ele conseguir então demora bastante tempo ainda até esse patamar (F2).

Ademais, para o F2 as dificuldades estão mais relacionadas à gestão da franquia, já que, para ele, o produto "roda sozinho". Entretanto, foi com a mudança do controle da empresa e com o início da profissionalização que houve uma mudança que foi um grande passo: 
Depois de 1 ano, 2 anos, eles criaram o que para mim foi um grande passo, que é a PEF: Programa de Excelência de Franquias que aí sim agora tinha um líder para cada departamento da escola, com as melhores práticas dentro desse estudo que eles fizeram $(\mathrm{F} 2)$.

Pelo relato do F2, foi possível corroborar com o que Nonaka e Takeuchi (1997) afirmam sobre a gestão do conhecimento estar relacionada ao processo de criação e disseminação de conhecimentos incorporando-os a novos produtos, serviços, tecnologias e sistemas.

A F3 relatou que não há dificuldades e que a franqueadora dá todo o suporte necessário, com visitas de consultores que sempre orientam da melhor forma possível. Além disso, são utilizados canais formais para a transferência do conhecimento:

\begin{abstract}
Eu acho que na verdade, eu não vejo dificuldade, porque a gente acaba tendo todo o suporte, ne. [...] Quando necessário, ne, a gente recebe a visita deles. Eles também têm acesso ao nosso sistema, então de acordo com a demanda de necessidade e de dúvidas, ne, eles repassam para a gente (F3).
\end{abstract}

Também na fala da F1 fica claro que não existem grandes dificuldades quanto ao acesso à informação para a resolução de questões rotineiras. Entretanto, a entrevistada relata que um fator inibidor da gestão do conhecimento no caso da franquia da qual faz parte é a concentração dos encontros regionais. Esses encontros, cujo objetivo é discutir assuntos referentes à gestão, ocorriam em diversas regiões por meio de representantes e com maior frequência. Hoje, eles acontecem em no máximo cinco regiões do Brasil, tornando o acesso do franqueador mais limitado.

De acordo com Ponchirolli e Fialho (2005), o propósito da gestão do conhecimento é alavancar o potencial das pessoas tornando esse ativo em uma maior produtividade para a empresa. Entretanto, percebeu-se que há uma dificuldade em mensurar essa transferência e absorção de conhecimento e que essa medição está mais relacionada a rotinas que devem ser cumpridas pelos funcionários:

\begin{abstract}
A gente mede em cima de resultado, aí não tem mais como medir não, é só no modo tácito, aí vai da gestão de cada franqueado. Eu fico medindo, quantas ligações você fez, quantos que você agendou para as pessoas virem e para quantas que você fechou, entendeu? Eu meço, mas isso não é muito comum entre os franqueados não. Quando eu falo isso com eles, eles ficam até de boca aberta (F2).
\end{abstract}

Não tem como medir um negócio hipotético, tem que fazer, ver o que deu e aí você faz a medição e faz as correções. Eu só consigo assim, tem gente que é genial e já consegue enxergar no futuro, infelizmente eu não tenho esse dom, quisera eu ter $(\mathrm{F} 2)$.

\title{
4 CONSIDERAÇÕES FINAIS
}

O objetivo deste artigo foi analisar a percepção dos franqueados em relação ao processo de transferência do know-how no sistema de franquias É interessante observar pelos depoimentos dos entrevistados que a gestão do conhecimento no sistema de franquias perpassa toda a estrutura sistêmica das empresas franqueadas, como afirmou Terra (2000) e assim envolve a alta administração - para dar um up na carreira, os franqueados precisam investir em cursos como o MBA; perpassam a cultura - os novos funcionários devem fazer 
cursos EAD para entender melhor sobre o produto e a marca: "existe esse processo de integração para um processo de transição do contratado para o conteúdo da marca" (F2); a estrutura organizacional e recursos humanos - em algumas franquias, existem consultores que orientam sobre diversas áreas: administrativa, comercial e pedagógica; os sistemas de informação - o conhecimento é repassado por meio de aparatos tecnológicos; e a mensuração de resultados - indicadores.

Notou-se que no sistema de franquias existe um aparato sistêmico para a transmissão do conhecimento - para a qual as ferramentas tecnológicas têm um importante papel - além dos treinamentos, encontros, congressos, competições e até MBA's. Verificou-se também que há uma certa rigidez quando se trata da inovação, já que os franqueados não têm liberdade para implantar medidas que acharem interessantes para a sua franquia, apesar de afirmarem que suas sugestões são ouvidas. Tudo deve passar pela aprovação dos franqueadores, já que se trata de um processo rígido de padronização. Porém, para os franqueados, isso não é um inibidor e sim um mitigador de riscos, pois, implantar mudanças isoladamente pode ser muito mais dispendioso e arriscado.

Foi possível perceber que as franqueadoras utilizam de estruturas formais e informais para repassar o conhecimento aos franqueados e que há um contato frequente entre as duas partes, existindo assim uma parceria de sucesso. Os principais fatores dificultadores apontados foram: o alto custo para os treinamentos; fazer com que os funcionários cumpram o que foi solicitado; e a diminuição do contato pessoal com o franqueador ao longo do tempo.

Como limitação deste estudo pode-se citar o fato de a pesquisa abordar apenas a visão do franqueado em relação à gestão do conhecimento. Assim, como sugestão para trabalhos futuros, recomenda-se investigar a percepção do franqueador, a fim de melhor compreender o relacionamento entre as duas partes envolvidas no processo de compartilhamento de conhecimento. Outra alternativa dentro dessa proposta de pesquisa seria analisar redes de franquias de outros segmentos ou ainda aprofundar os estudos em torno de uma única rede. 


\section{REFERÊNCIAS}

ABDALA, D. O S.; GONÇALVES, C. A. Sustentabilidade e crescimento de redes de franquias. Estudo \& Debate, v. 21, n. 2, p. 161-179, 2014.

ALAVI, M.; LEIDNER, D. E. Knowledge Management and Knowledge Management Systems: Conceptual Foundations and RESEARCH Issues. MIS Quarterly, v. 25, n. 1, p.107-136, 2001.

ARAÚJO, D. L. A.; POPADIUK, S. Barreiras inerentes à transferência de conhecimento: um estudo sob a perspectiva de franqueados do segmento de escolas de idiomas. Organizações em contexto, v. 11, n. 21, p. 241-278, 2015.

ASSOCIAÇÃO BRASILEIRA DE FRANCHISING. Desempenho do franchising 2017. 2017. Disponível em: https://www.abf.com.br/wp-content/uploads/2018/03/Desempenho-doFranchising-2017.pdf. Acesso em: 20 mai. 2018.

ASSOCIAÇÃO BRASILEIRA DE FRANCHISING. Portal do Franchising. 2018. Disponível em: https://www.portaldofranchising.com.br/. Acesso em: 20 mai. 2018.

BARBOSA, E. R. Gestão do conhecimento e o uso estratégico de tecnologias de informação: um estudo em redes de franquias no Estado do Rio Grande do Norte. 2010. 141 f. (Dissertação de Mestrado). Universidade Federal do Rio Grande do Norte, Natal.

BARDIN, L. Análise de conteúdo. Tradução Luís Antero Reto e Augusto Pinheiro. São Paulo: Edições 70, 2002.

BRASIL. Lei $\mathbf{n}^{\circ} \mathbf{8 . 9 5 5}$, de 15 de dezembro de 1994. Dispõe sobre o contrato de franquia empresarial (franchising) e dá outras providências. Disponível em: http://www.planalto.gov.br/ccivil_03/leis/18955.htm. Acesso em: 20 mai. 2018.

CHERMAN, A; ROCHA-PINTO, S. R. Valoração do conhecimento nas organizações e sua incorporação nas práticas e rotinas organizacionais. Revista Brasileira de Gestão de Negócios, v. 18, n. 61, p. 416-435, 2016.

CHIZZOTTI, A. Pesquisa em ciências humanas e sociais. Vozes: Petrópolis, 2006.

COUGHLAN, A. T.; ANDERSON, E.; STERN, L.W.; El-ANSARY, A. I. Canais de marketing. 7. ed. São Paulo: Pearson Education do Brasil, 2012.

DALKIR, K. Knowledge management in theory and practice. Burlington: Elsevier Butterworth-Heinemann, 2005.

GIGLIOTI, B. S. Transferência de conhecimento nas franquias brasileiras. 2010. $110 \mathrm{f}$. (Dissertação de Mestrado). Escola de Administração de Empresas de São Paulo. Fundação Getúlio Vargas, São Paulo.

FEITOSA, I. L. Transferência de conhecimentos em franquias. 2010. 226 f. (Tese de Doutorado). Universidade Presbiteriana Mackenzie, São Paulo. 
INTERNATIONAL FRANCHISE ASSOCIATION. What is a franchise. 2018. Disponível em: http://www.franchise.org/what-is-a-franchise. Acesso em: 20 mai. 2018.

JIMÉNEZ-BARRIONUEVO, M. M.; GARCÍA-MORALES， V. J.; MOLINA， L. M. Validation of an instrument to measure absorptive capacity. Technovation, v. 31, n. 5/6, p. 190-202, 2011.

KOGUT, B.; ZANDER, U. Knowledge of the firm, combinative capabilities, and the replication of technology. Organization Science, v. 3, n. 3, p. 383-397, 1992.

KOROWAJCZUK, A.; CASTILHO, B. S. C.; COSSICH, E. J.; FRÓES, F. J. C. S.; FERRÃ̃O, G. S. Avaliação de organizações em relação à gestão do conhecimento com base nos critérios de excelência da Fundação do Prêmio Nacional de Qualidade. In: ANAIS DO CONGRESSO BRASILEIRO DE BIBLIOTECONOMIA E DOCUMENTAÇÃO, Porto Alegre, 2000.

LARA, C. R. D. A atual gestão do conhecimento: a importância de avaliar e identificar o capital intelectual nas organizações. São Paulo: Nobel, 2004.

MAURO, P. C. Guia do franqueado: como fazer sua empresa crescer com o franchising. 4. ed. São Paulo: Nobel, 2007.

NONAKA, I.; TAKEUCHI, H. Criação de conhecimento na empresa: como as empresas japonesas geram a dinâmica da inovação. Rio de Janeiro: Elsevier, 1997.

PÉRSICO, J. A.; PAULA, J. Franquias. SEBRAE. 2013. Disponível em: http://www.sebrae.com.br/Sebrae/Portal\%20Sebrae/Anexos/franquias_portal_sebrae.pdf. Acesso em: 20 mai. 2018.

ROSSETTI, A. G.; MORALES, A. B. T. O papel da tecnologia da informação na gestão do conhecimento. Ciência da Informação, v. 36, n. 1, p. 124-135, 2007.

SANTOS, A. R.; PACHECO, F. F.; PEREIRA, H. J.; BASTOS JÚNIOR, P. A. Gestão do conhecimento: uma experiência para o sucesso empresarial. Curitiba: Champagnat, 2001.

STEFANO, N. M.; CASAROTTO FILHO, N.; FREITAS, M. C. D.; MARTINEZ, M. A. T. Gestão de ativos intangíveis: implicações e relações da gestão do conhecimento e capital intelectual. Perspectivas em Gestão \& Conhecimento, v. 4, n. 1, p. 22-37, 2014.

SZULANSKI, G. Exploring internal stickiness: impediments to the transfer of best practice within the firm. Strategic Management Journal, v. 17, n. 2, p. 27-43, 1996.

TERRA, J. C. C. Gestão do conhecimento: o grande desafio empresarial: uma abordagem baseada no aprendizado e na criatividade. São Paulo: Negócio, 2000.

TSOUKAS, H. What is Organizational Knowledge?. Journal of Management Studies, v. 38, n. 7, p. 973-993, 2001.

VERGARA, S. C. Projetos e relatórios de pesquisa em administração. 14. ed. São Paulo: Atlas, 2013. 
YIN, R. K. Estudo de caso, planejamento e métodos. 2. ed. São Paulo: Bookman, 2001.

ZAHRA, S. A.; GEORGE, G. Absorptive capacity: a review, reconceptualization, and extension. Academy of Management Review, v. 27, n. 2, p. 185-203, 2002. 